\title{
Study on Evaluation of Ecological Environment Quality and Temporal-Spatial Evolution of Danjiang River Basin (Henan Section)
}

\author{
Shi-Dong Wang, Jin-Jin Si*, Yong Wang \\ School of Surveying and Land Information Engineering, Henan Polytechnic University, Jiaozuo,
} Henan 454000, P.R. China

Received: 28 April 2020

Accepted: 3 October 2020

\begin{abstract}
The Danjiang River Basin (Henan Section) is the water source of the Middle Route of the South-toNorth Water Transfer Project. Its ecological environment quality has received increasing attention. In this study, on the basis of the ecological environment of the study area, we constructed the evaluation index system from four aspects: ecological basis, ecological structure, ecological stress and ecological benefits. The variable fuzzy set model was improved by using the central point triangle whitening weight function and the relative difference function. The ecological environment quality of the Danjiang River Basin (Henan Section) in the past 20 years was evaluated, and the evolution patterns and causes of ecological environment quality were analyzed by combination with land use changing. And the results showed that the area with better ecological environment quality was significantly larger than the deterioration area. The area with poorer grade was decreased from $441.22 \mathrm{~km}^{2}$ in 1998 to $3.93 \mathrm{~km}^{2}$ in 2017 , and its proportion was correspondingly decreased from $2.23 \%$ to $0.05 \%$. The area with the ordinary grade was decreased from $4528.79 \mathrm{~km}^{2}$ in 1998 to $2636.47 \mathrm{~km}^{2}$ in 2017 , and its proportion was correspondingly decreased from $53.67 \%$ to $31.24 \%$; The moderately graded area was increased from $3132.7 \mathrm{~km}^{2}$ in 1998 to $5206.88 \mathrm{~km}^{2}$ in 2017 , and its proportion was increased from $37.12 \%$ to $61.71 \%$; the area with good grade was increased from $319.58 \mathrm{~km}^{2}$ in 1998 to $579.01 \mathrm{~km}^{2}$ in 2017 , the area with the excellent grade of an evaluation rating was almost unchanged. Based on the evaluation results, the spatial correlation analysis of changes in habitat quality was further carried out. The autocorrelation index was 0.5122 , which indicating that the changes in ecological environment quality in the study area has a strong spatial aggregation characteristics. Combined with the change in land use changing in the present study, we found that the human activities were the major factor causing the changes in ecological environment quality in the study area. These results can provide certain theoretical basis and
\end{abstract}


technical support for land development and utilization as well as for the ecological protection in the study area.

Keywords: Danjiang River Basin (Henan Section), variable fuzzy set, ecological environment quality, spatial autocorrelation

\section{Introduction}

As the main means of the carrier in the human production and life, land resources are the essential basis for human survival and development, and also for the carrier of various complex ecosystems on the Earth [1]. Since the 1980s, accompanied the acceleration of urbanization, the continuous improvement of industrialization level and the rapid growth of population, people's development and utilization of land resources have been continuously strengthened [2-3], which have triggered a series of problems in ecosystem quality, including heat island effect [4], water pollution [5] and biodiversity reduction [6-7], having imposed more serious and negative impacts on food production, human survival and sustainable development. Ecological environment quality, which refers to the extent of ecological environment affect human survival and socio-economic development within a certain time and space, and is the objective existence of the basic attributes of the ecological environment [8]. The distribution of water resources in China is much imbalanced. The middle-route of the South-to-North Water Transfer Project is of great significance for relieving the water resource shortage problem in northern China. As the main water source of the Middle Route of the South-to-North Water Transfer Project, which need to ensure and enhance the ecological environment quality of the Danjiang River Basin (Henan Section) and its surrounding areas. Thus, it has become the primary goal of maintaining long-term, stable and safe operation of the Central Line Project of South-to-North Water Diversion. Viewing from the current development trend, the implementation of the project will inevitably lead to the changes in the land use patterns of the region, resulting in the changes in the ecological environment quality of the study area. Therefore, analyzing the changes in ecological environment quality is of great importance in term of the protection of regional biodiversity, and is the basic condition for ecological protection and rational planning and utilization of natural resources, in turn, which will help to maintain the balance and sustainable development of regional natural ecosystems [9].

Ecological environment quality evaluation, which refers to the evaluation of the ecological environment quality and its influence relationship based on a series of the selected indicator systems and evaluation criteria [10]. At the present, there are two main methods of researches: the first method is based on the various model evaluation methods, such as ecological environment suitability index model (HSI) [11-12], SolVES model [13], and MaxEnt model [14-15], etc, the ecological environment quality module in the InVEST model is the most widely used and mature ecological environment quality evaluation method in the present [16-19]. In recent years, a large number of related researches which based on the model have been done to evaluate and analyze the ecological environment quality in different regions. The other type of research is evaluating the ecological environment quality in different scales based on the ecological environment quality evaluation index system. The selected indicators mainly include the natural state, slope, aspect, landscape pattern and human impact of the study area [20-23]. However, in the current researches, the indicator system of ecological environment quality is short of a unified construction standard, and the evaluation method is too simple, which is the main cause that affects the results of ecological environment quality evaluation. Therefore, in the follow-up study, it's necessary to construct an indicator system reflecting the characteristics of ecological environment quality in the study area and adopt a more scientifically reasonable evaluation method.

With the implementation of the South-to-North Water Transfer Project, the ecological environment quality of the Danjiang River Basin (Henan Section) has been disturbed obviously by human activities. According to the characteristics of the study area, it's of great importance to screen out the ecological environment quality evaluation indexes of the basin and to construct a reasonable evaluation index system for analyzing the changes in ecological environment quality, which will include its temporal and spatial evolution. Based on the above research objectives, in this study, we construct an ecological environment quality evaluation index system suitable for the study area based on the ecological basis, ecological structure, ecological benefits and ecological stress. The grid is selected as the evaluation unit, and the analytic hierarchy process and entropy are used, and combined the weighting method to query the weights of the evaluation indicators, and the central point triangle whitening weight function and the relative difference function are applied to improve the variable fuzzy set evaluation model, and, then, we evaluate the ecological environment quality of the research area in the past 20 years. The temporal and spatial evolution of ecological environment quality in combination with the land use change is conducted. 


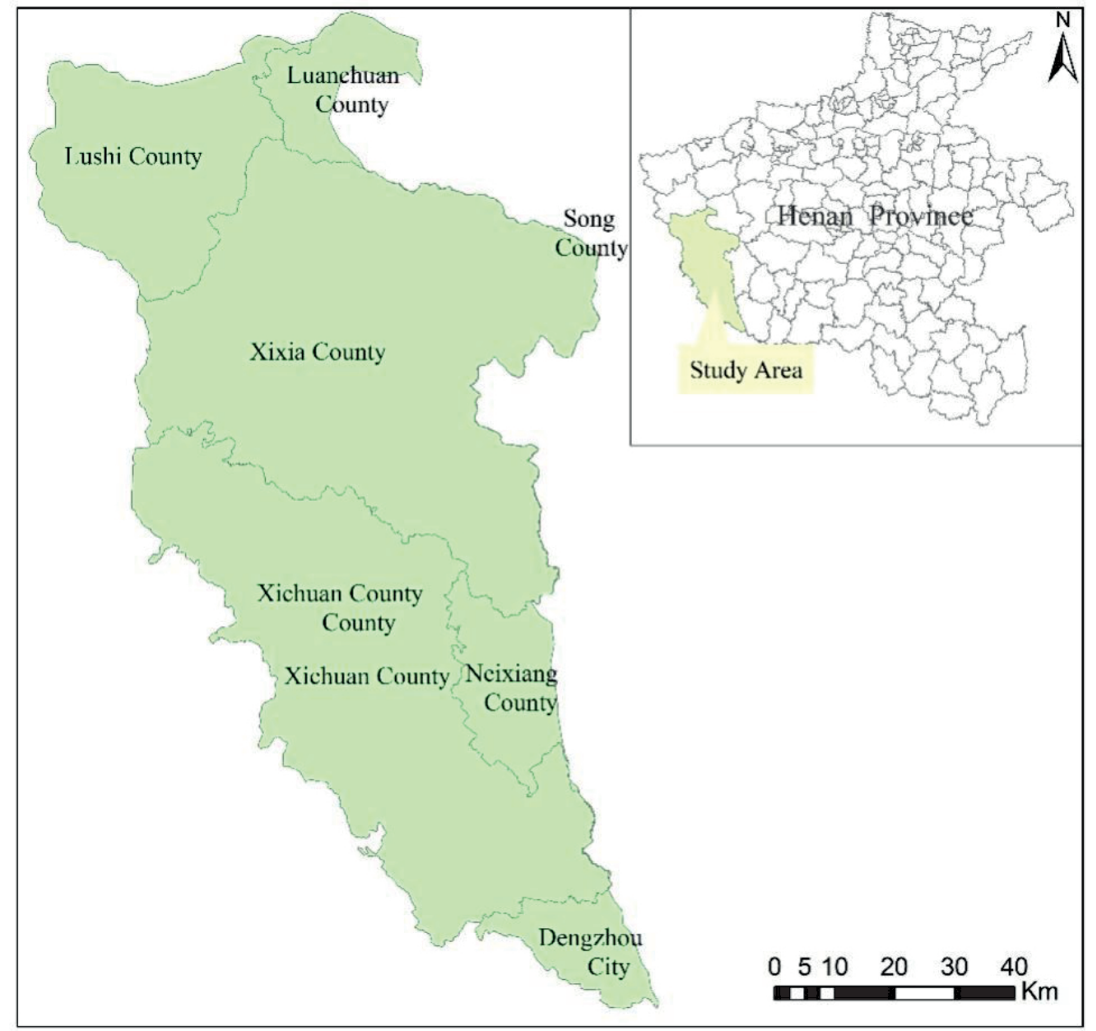

Fig. 1. The geographical location map of the study area.

\section{Study Area and Data}

\section{Study Area}

The Danjiang River Basin (Henan Section) is located in the southwestern part of Henan province, as shown in Fig. 1. It is adjacent to Hubei province and Shaanxi province in the Qinling Mountains. It consists of several townships in Lushi County of Sanmenxia City, several townships in Luanchuan County of Luoyang City, and Nanyang City. Xixia County, Luanchuan County, and several townships in Neixiang County and Dengzhou City, with a total area of $8438.29 \mathrm{~km}^{2}$, including $6978 \mathrm{~km}^{2}$ in Nanyang City, $1132 \mathrm{~km}^{2}$ in Sanmenxia City, and $328 \mathrm{~km}^{2}$ in Luoyang City, geographical coordinates were between and $110^{\circ} 52^{\prime} \mathrm{E}-112^{\circ} \mathrm{E}$ and $33^{\circ} 30^{\circ} \mathrm{N}-34^{\circ} \mathrm{N}$. The study area is located in the transition zone from the northern subtropical zone to the temperate zone. The forest land area is about $4280 \mathrm{~km}^{2}$ and mainly distributed in the western and northern mountainous areas. The cultivated land area is about $1470 \mathrm{~km}^{2}$, which is mainly distributed in the plains and hilly areas in the central and southeastern parts. The urbanization level is low, accounting for only about $3 \%$ of the total area of the study area.

\section{Data}

The basic remote sensing data used in this study are Landsat series remote sensing images, the sensors are
Landsat 5-TM and Landsat 8-OLI, respectively. The imaging times were September 1998, September 2008 and August 2017, respectively, to avoid the errors of different vegetation growth periods. Firstly, the image was cut in ENVI5.1, referring to the classification system of the national land use and in combination with the actual land use in the study area. The land use types of the study area were determined as forest land, grassland, water area, bare land, construction land and cultivated land, as shown in the Fig. 2. The support vector machine was used to classify the images and obtain the preliminary classification results of the study area; Based on this, classification results are processed, misclassified pixels are corrected according to relevant data such as field surveys and current land use maps, and finally land use classification results for the survey area are obtained. Samples were randomly collected in the study area, and the classification confusion matrix and Kappa coefficient of the three-stage images were calculated by ENVI 5.1. The results obtained were $0.82,0.86$ and 0.83 , respectively, indicating that the classification results are better. Various landscape pattern indicators, ecological land use ratio, land use intensity and other indicators were calculated based on the image classification results; the annual average rainfall index was obtained by Kriging interpolation according to the meteorological data of the China Meteorological Data Network; data, such as NPP (Net Primary Productivity), were calculated according to the data source of the International Scientific Data Service 

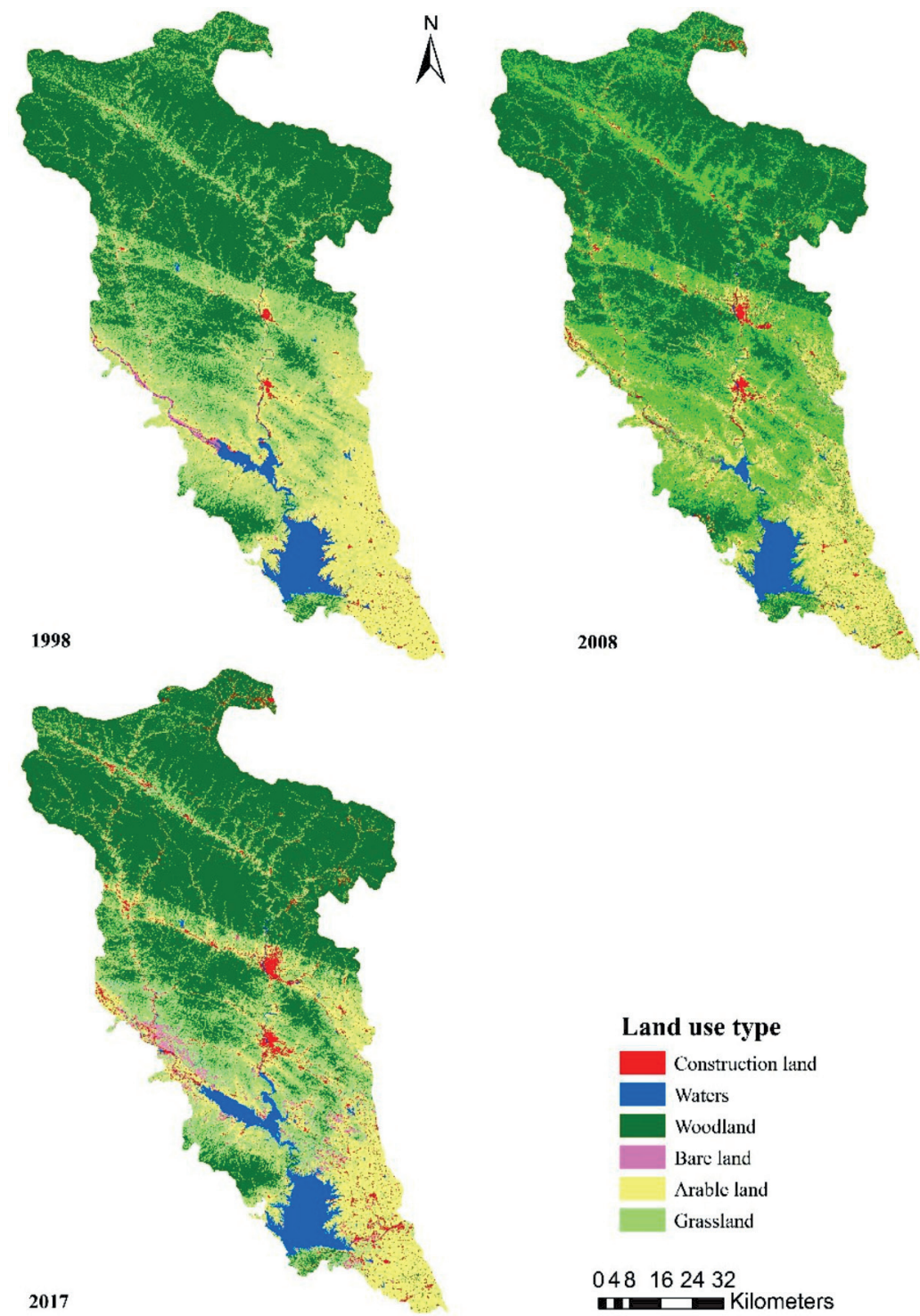

048162432

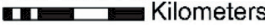

Fig. 2. Land use classification map of the study area.

Platform; the population and per capita GDP indicators were obtained by looking up the Statistical Yearbook of the study area.

\section{Methods}

\section{Selection and Calculation of Evaluation Indexes}

Based on the theories of sustainable development, landscape ecology and regional science, we selected the following indicators based on the ecological basis, ecological structure, ecological benefits and ecological stress area according to the ecological status and socioeconomic development of the study area. An ecological environment quality evaluation indexs system was constructed for the study area, as shown in the Table 1.

In this study, a grid of $1 \mathrm{~km} \times 1 \mathrm{~km}$ was used as the evaluation unit of the study area.
(1) Remote sensing ecological index (RSEI): This index can quickly monitor and reflect the regional ecological environment quality, which including inversion indicators such as greenness, humidity, heat, and dryness [24-27].

$$
R S E I=f(N D V I, \text { Wet }, L S T, N D S I)
$$

...where NDVI represents the greenness index; Wet represents the humidity index; $L S T$ represents the heat index; and NDSI represents the dryness index.

(2) Topographic index: A comprehensive index describes the topographic relief of the study area. The terrain index can effectively reflect the combined effects of terrain elevation and terrain slope on the spatial distribution of landscape [28]. The calculation formula of the terrain bit index based on DEM data is as follows: 
Table 1. Ecological environment quality evaluation indexs system in the study area.

\begin{tabular}{|c|c|c|}
\hline Criteria layer & Index & Attributes \\
\hline \multirow{5}{*}{ Ecological basis } & RSEI & Positive indicator \\
\hline & Annual rainfall & Interval indicator \\
\hline & Effective soil thickness & Positive indicator \\
\hline & Terrain index & Positive indicator \\
\hline & NPP & Positive indicator \\
\hline \multirow{5}{*}{ Ecological structure } & Diversity index & Positive indicator \\
\hline & Uniformity index & Positive indicator \\
\hline & Fragmentation index & Negative indicator \\
\hline & Dominance index & Positive indicator \\
\hline & Ecological land use ratio & Positive indicator \\
\hline \multirow{3}{*}{ Ecological stress } & Population density & Negative indicator \\
\hline & Urbanization ratio & Negative indicator \\
\hline & Land use intensity & Negative indicator \\
\hline \multirow{2}{*}{ Ecological benefits } & Per capita GDP & Positive indicator \\
\hline & Ecological service value & Positive indicator \\
\hline
\end{tabular}

$$
T=\log _{10}\left[\left(\frac{H}{H_{\text {meam }}}+1\right) \times\left(\frac{S}{S_{\text {meam }}}+1\right)\right]
$$

...where $T$ is the topographic index, $H$ and $S$ are the elevation and slope values of the study area respectively. $H_{\text {mean }}$ and $S_{\text {mean }}$ are the average elevation values and average slope value in the study area.

(3) Diversity index: The diversity index reflects the quantity of land types in the study area, the uniformity of land types with different proportions of land types [29]. The calculation formula is as follows:

$$
H=-\sum_{i=1}^{m}\left(p_{i}\right) \times \ln \left(p_{i}\right)
$$

...where $P i$ is the proportion of land type $i ; m$ is the number of land use types.

(4) Uniformity index: The uniformity index was mainly used to describe the uniformity degree of distribution of different types of land use. The calculation formula is as follows:

$$
E=H / H_{\max }
$$

...where $H_{\max }=\ln (m)$ refers to the diversity index in the maximum uniform state, which ranges from $[0,1]$.

(5) Dominance index: The dominance index was used to reflect the deviation between the land use diversity and maximum diversity, indicating the extent to which a certain land type dominates the land use types. The calculation formula is as follows:

$$
D=H_{\max }-H=H_{\max }+\sum_{i=1}^{m}\left(p_{i}\right) \times \ln \left(p_{i}\right)
$$

...where $H_{\max }=\operatorname{lnm}$. The greater the dominance degree is, the more obvious advantage of certain land types have.

(6) Fragmentation index: The fragmentation index was used to describe the complexity of the spatial structure of land use and can reflect the interference degree of landscape types by natural and human factors. The calculation formula is as follows:

$$
F=(N P-1) / N C
$$

...where $N P$ is the total number of plaques of land use type and $N C$ represents the area of the study area divided by the minimum plaque area.

(7) Land use intensity: This index reflects the degree of human use of land under social and economic activities. The calculation formula is as follows:

$$
L=\sum_{i=1}^{n} A_{i} C_{i} \times 100 \%
$$

...where $L$ is the land use intensity index, $A_{i}$ is the indicator which describe the classification factor of a certain land use type, and $C_{i}$ is the percentage of the land use type to the total area of the study area; and $n$ is the number of land use types.

(8) Proportion of ecological land: Ecological land types are mainly divided into forest land, grassland, 
waters, tidal flats, wetlands and other ecological land [30]. Its calculation formula is as follows:

$$
Z=C / S
$$

...where $Z$ is the proportion of ecological land, $C$ is the total area of ecological land in the study area, and $Q$ is the total area of the study area.

(9) Population density and per capita GDP: Data from the township population and per capita GDP of the townships in the study area in 1998, 2008, and 2017 were obtained from the statistical yearbook of the study area, and assigned to the Danjiang River Basin (Henan Section) by ArcGIS. In the administrative division map, the population density and per capita GDP data are calculated according to the area of each township.

(10) Eco-service value (ESV): ESV refers to the direct or indirect acquisition of various products and services through different land ecological environment values in the process of human transformation of land, which can be quantified by the value of ecological services [31-32]. The calculation formula is as follows:

$$
E S V=\sum_{i=1}^{n} A_{i} \times V_{i}
$$

...where $E S V$ is the total value of ecological service value; $A I$ is the area of the $i$-th land use type in the study area and its unit is $\mathrm{hm}^{2}$; and $V i$ is the ecological service value coefficient of the $i$-th land use type and its unit is Yuan $/ h m^{2}$.

\section{Determination of Index Weight}

The weight of the evaluation index can reflect the importance of the evaluation process, and different weights often result in different evaluation results. The commonly used index weighting methods include expert scoring, analytic hierarchy process, coefficient of variation method, and entropy weight method. In order to improve the accuracy and objectivity of weights, we used analytic hierarchy process and entropy weight method in combination with weights to determine the index weights.

\section{Analytic Hierarchy Process}

AHP mainly obtains the judgment matrix by evaluating the evaluation indexes, calculates the normalized eigenvector of the judgment matrix, and obtains the weight $\omega_{i}$ of the $i$-th evaluation index. Finally, the consistency of the obtained results was tested [33].

\section{Entropy Weight Method}

Entropy is a concept derived from thermodynamics. In 1948, Shannon first introduced information entropy to describe the uncertainty of the signal from the source, which is a way to measure the order of the system in the first order [34]. The smaller the information entropy of an evaluation metric, the greater the degree of change in the metric, the greater the amount of information provided by the metric, and the greater the weight. The steps to determine the weight of an index using the entropy weight method are as follows:

(1) Standardization of Initial Indexes

The original evaluation index matrix $X$ was constructed, a total of $\mathrm{m}$ evaluation indexes were set, $n$ refers to the evaluation objects and the index matrix is:

$$
X=\left(x_{i j}\right)_{m \times n}=\left(\begin{array}{cccc}
x_{11} & x_{21} & \ldots & x_{1 n} \\
x_{21} & x_{22} & \ldots & x_{2 n} \\
\ldots & \ldots & \ldots & \ldots \\
x_{m 1} & x_{m 2} & \ldots & x_{m n}
\end{array}\right)
$$

After standardizing the matrix, $P=\left(p_{i j}\right)_{m \times n}$, where $p_{i j}\left(0 \leq p_{i j} \leq 1\right)$ is the standard value of the $j$ th criterion on the index $i$.

(2) Define Index Information Entropy

The entropy of the ith index was defined as follows:

$$
e_{i}=-k \sum_{j=1}^{n} z_{i j} \ln z_{i j},(1 \leq z \leq m)
$$

...where $z_{i j}=\frac{p_{i j}}{\sum_{j=1}^{n} p_{i j}}, \mathrm{k}=\frac{1}{\ln n}$, and when $z_{i j}=0$, given $z_{i j} \ln z_{i j}=0$.

(3) Determination of Index Weights

Based on the index information entropy, the entropy weight of the index is defined as:

$$
\omega_{2 i}=\frac{1-e_{2 i}}{m-\sum_{i=1}^{m} e_{2 i}}
$$

...where $0 \leq \omega_{2 i} \leq 1, \sum_{i=1}^{m} \omega_{2 i}=1$.

Combination Weight Calculation

AHP focuses on the subjective preference of decision makers. The entropy weight method focuses on the objective information contained in the data itself. Therefore, it is necessary to consider two methods to determine the index weights. Its calculation formula is:

$$
\omega=\alpha \omega_{1 i}+(1-\alpha) \omega_{2 i}
$$

...where, $\alpha$ is focus coefficient and $0 \leq \alpha \leq 1$. Comprehensively considering the relationship between the indicators, the value of $\alpha$ was set as 0.5 .

\section{Evaluation Method}

Based on the fuzzy mathematics, the variable fuzzy set theory calculates the pros and cons of each evaluation 
index from the perspective of relative membership degree, and in combination with the weighting method to evaluate the ecological environment quality of the study area [35-38]. The main process of variable fuzzy set theory is to first establish the opposite fuzzy set and relative difference function of each evaluation index, then the relative difference function and the central point triangle whitening weight function was used to calculate the relative membership degree, and finally carry out the fuzzy variable evaluation. The specific steps are as follows: 1.Opposite Fuzzy Sets and Relative Difference Functions.

Chen [38] proposed that the source and motivation of the movement of things originated from the opposition and unity of the contradictions according to the contradictory principle of movement in the dialectics of nature. According to this proposal, the nature of the contradictions was given to $A$ and $A^{C}$, and the occurrence of things was given. The equilibrium bound of mass change is defined as: the relative membership degree $\mu_{\mathrm{A}}(u)$ of the attraction property A of the fuzzy concept and the relative membership degree $u_{A}^{c}(u)$ of the repulsive property $A^{C}$ reach a dynamic equilibrium, i.e. $\mu_{\mathrm{A}}(u)=\mu_{\mathrm{A}} \mathrm{c}(u)$.

Definition 1: The opposite fuzzy concept (things, phenomena) was set on the domain $U$, and the attraction and exclusion properties were dented by $A$ and $A^{C}$. For any element $u$ in $U, u \in U$ is met, reference continuous interval $[1,0]$ (to $A$ ) and $[1,0]$ (to $A^{C}$ ) at any point. The relative membership of attraction and exclusion are $\mu_{\mathrm{A}}(u), \mu_{\mathrm{A}} \mathrm{c}(u)$, and $\mu_{\mathrm{A}}(u)+\mu_{\mathrm{A}} \mathrm{c}(u)=1$ (Fig. 3). Given that

$$
A=\left\{u, \mu_{A}(u), \mu_{A} c(u) \mid u \in U\right\}
$$

Meet $\mu_{\mathrm{A}}(u)+\mu_{\mathrm{A}} \mathrm{c}(u)=1,0 \leq \mu_{\mathrm{A}}(u) \leq 1,0 \leq \mu_{\mathrm{A}} \mathrm{c}(u) \leq 1$, $A$ is known as the opposite fuzzy set of $U$.

Definition 2: Set

$$
D_{A}(u)=\mu_{A}(u)-\mu_{A} c(u)
$$

$\mathrm{D}_{A}(u)$ is known as the relative difference of $u$ to $\mathrm{D}_{A}$, map to:

$$
\begin{aligned}
& D_{A}: D \rightarrow[-1,1] \\
& u \mapsto D_{A}(u) \in[-1,1]
\end{aligned}
$$

The formula is known as the relative difference function of $u$ versus $A$ (Fig. 3).
Definition 3: Let $U$ be the domain, $u$ be any element in $U u \in U . \mu_{\mathrm{A}}(u)$ and $\mu_{\mathrm{A}} \mathrm{c}(u)$, the relative membership degree of the property $A$ and the degree of $A^{C}$ repulsion property of the thing $u$ satisfy the definition of the opposite fuzzy set formula (14), respectively, given that

$V=\left\{(u, D) \mid u \in U, D_{A}(u)=\mu_{A}(u)-\mu_{A} c(u), D \in[-1,1]\right\}$

$V$ is known as the fuzzy variable set of $U$.

\section{Relative Membership Calculation}

(1) Relative Difference Function Model

Set $X_{0}=[a, b]$ as the attraction domain of the fuzzy variable and set $\mathrm{V}$ to the real axis, i.e. $0 \leq D_{A}(u) \leq 1$ interval, $X=[c, d]$ is set as a range of upper and lower bounds, including $X_{0}\left(X_{0} \subset X\right)$, as shown in Fig. 3 .

Set $M$ as the point value of $\mu_{\mathrm{A}}(\mathrm{u})=1$ in the attraction domain interval $[a, b]$, where $M$ is not necessarily the midpoint value of the interval $[a, b], x$ is the value of any point in the interval $[a, b]$. When $x$ falls to the left of the $M$ point, the relative function difference model is:

$$
\left\{\begin{array}{l}
D_{A}(u)=(x-a /)^{\beta} \quad x \in[a, M] \\
D_{A}(u)=-\left(\frac{x-a}{c-a}\right)^{\beta} \quad x \in[c, a]
\end{array}\right.
$$

When $x$ falls to the right of point $M$, the relative function difference model is:

$$
\left\{\begin{array}{l}
D_{A}(u)=\left(\frac{x-b}{M-b}\right)^{\beta} \quad x \in[M, b] \\
D_{A}(u)=-\left(\frac{x-b}{d-a}\right)^{\beta} \quad x \in[b, d]
\end{array}\right.
$$

When $x$ falls outside the $X$ interval

$$
D_{A}(u)=0 x \notin[c, d]
$$

...where $\beta$ is a non-negative index, usually $\beta=1$, that is, the relative difference function model is a linear function. Therefore, the relative membership degree $u_{\mathrm{A} 1}$ (u) of the index $x$ can be solved by the relative difference

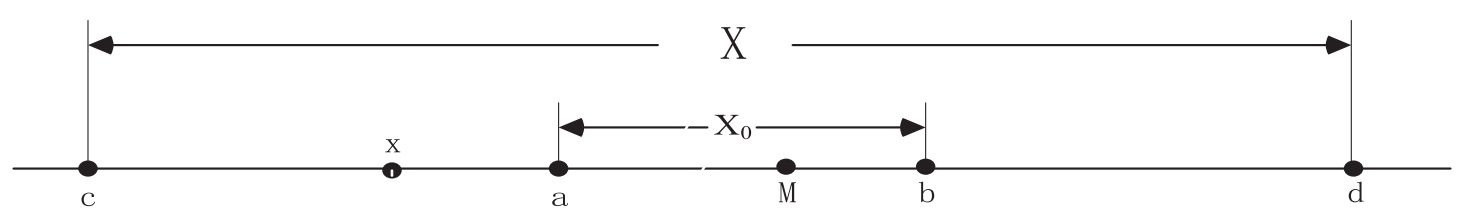

Fig. 3. Relative function difference model. 
function, and the calculation formula is as shown in the equation (21).

$$
\mu_{A 1}(u)=\frac{1+D_{A}(u)}{2}
$$

(2) Center Point Triangle Whitening Weight Function

Grey whitening weight function clustering is a clustering method that uses the whitening weight function of gray class to divide the research evaluation index into several defined categories, which can more accurately determine the gray interval attribute and make the evaluation result more scientifically reliable. It mainly determines the strength and weakness of the evaluation object by measuring the gray clustering coefficient of the index, and then performs the grade discrimination [39-40]. The central point triangle whitening weight function calculates the membership degree of each index by determining the center point of the gray class, and the evaluation result was calculated by combining the index weights.

The procedure for calculating the relative membership based on the whitening weight function of the center point triangle is as follows: according to the evaluation requirements of the indicators, the range of values of the evaluation indicators is defined as having a difference interval. For example, the value range $\left(a_{1}, a_{k}\right)$ of the indicator was divided into $\left[a_{1}, a_{2}\right], \ldots$, $\left[\begin{array}{ll}a_{k-1}, & a_{k}\end{array}\right], \ldots, \quad\left[a_{s-1}, a_{s}\right], \quad\left[\begin{array}{ll}a_{k}, & a_{s+1}\end{array}\right]$, among which $\mathrm{k}=1,2, \ldots, \mathrm{s}$. Set $\lambda$ as the center point of the $k t h$ interval, i.e. $\lambda_{k}=\left(a_{k}, a_{k+1}\right) / 2$.

In order to ensure the integrity of the whitening function of the observation interval in the $S$ interval of the first interval, the interval is extended to the left and right direction, and the 0 interval and the $s+1$ interval were added to obtain a complete center point sequence.: $\lambda_{0}, \lambda_{1}, \ldots \lambda_{s}, \lambda_{s+1}$. Then the sample observation value $x i$ of the index $i$ was calculated by the formula (22) to calculate its relative membership degree:

$$
\mu_{A 2}(u)=\left\{\begin{array}{cc}
0 & x \notin\left[\lambda_{k-1}, \lambda_{k+1}\right] \\
\left(x-\lambda_{k-1}\right) /\left(\lambda_{k}-\lambda_{k-1}\right) & x \in\left[\lambda_{k-1}, \lambda_{k}\right] \\
\left(\lambda_{k+1}-x\right) /\left(\lambda_{k+1}-\lambda_{k}\right) & x \in\left(\lambda_{k}, \lambda_{k+1}\right]
\end{array}\right.
$$

Therefore, the relative membership of the index is the following:

$$
\mu_{A}(u)=\left(\mu_{A 1}(u)+\mu_{A 2}(u)\right) / 2
$$

\section{Fuzzy Variable Evaluation}

Let the evaluation object $u$ establish the number of indicators to be considered in the evaluation system as $m$ according to the actual analysis, and the index feature value vector is as follows:

$$
\vec{x}=\geq\left(x_{1}, x_{2}, \ldots, x_{m}\right)=x_{i} \vec{x}=\left(x_{1}, x_{2}, \ldots, x_{m}\right)=x_{i}
$$

...where $i$ is the evaluation indicator serial number, $i=1,2, \ldots m$. Then the relative membership vector $\vec{\mu}_{A}(u)$ of the object $u$ with respect to $m$ indicators is as follows:

$$
\vec{\mu}(u)=\left(\mu_{A}(u)_{1}, \mu_{A}(u)_{2} \ldots \mu_{A}(u)_{m}\right)
$$

Set the weight vector of $m$ indicator to $\vec{\omega}=\left(\begin{array}{lll}\omega_{1} \omega_{2} & \cdots & \omega_{m}\end{array}\right)=\omega_{i}, \quad$ and satisfied $\sum_{i=1}^{m} \omega_{i}=1$, then the evaluation model of the variable fuzzy set is:

$$
v_{A}(u)=\left\{1+\sum_{i=1}^{m}\left[\frac{\omega_{i}\left(1-\mu_{A}(u)_{i}\right)^{p}}{\omega_{i}\left(\mu_{A}(u)_{i}\right)^{p}}\right]^{\frac{\alpha}{p}}\right\}^{-1}
$$

$v_{A}(u)$ to evaluate the relative membership of the object $u$ with respect to the level $\mathrm{R}$, where $\alpha$ is the model optimization criterion parameter and $p$ is the distance parameter, the value can be selected from 1,2 .

The appropriate $\alpha$ and $p$ parameters are selected, and the comprehensive relative membership degree of each evaluation unit with respect to each level $R$ is calculated, and the evaluation result was calculated by combining the level feature values. Its calculation formula is:

$$
H=(0.2,0.4, \ldots, 1) * \vec{v}_{A}(u)_{h}^{T}
$$

In the improved variable fuzzy set theory, the introduced central point triangle whitening weight function provides a new idea and method for the calculation of relative membership degree. The comprehensive relative membership degree obtained by these two methods can avoid the deviation caused by the calculation process and ensure the calculation result is more reasonable and accurate.

\section{Results and Analysis}

\section{Ecological Environment Quality Evaluation Results}

Based on the grid evaluation unit, the evaluation indexes of the study area was extracted, the information of each unit's indexes were statistically evaluated and its relative membership degree with respect to each level 
was calculated, and the generalized weight distance of the index was calculated according to the index weight. On the basis, each evaluation was obtained. The comprehensive relative membership of the level and the final evaluation result was calculated by using the level feature value. The evaluation results were divided into five levels of difference [0-0.2], ordinary (0.2-0.4], moderate (0.4-0.6], good (0.6-0.8] and excellent (0.8-1] at equal intervals in ArcGIS. The ecological environment quality level distribution map of the study area (Fig. 4) was produced, and the area and proportion of the ecological environment quality of each grade were counted. The results are shown in Table 2 .

It can be seen from Fig. 4 that from 1998 to 2017, the overall ecosystem quality of the Danjiang River Basin (Henan Section) showed a clear trend, and the change was the most significant in the central part of the study area. In 1998, the ecosystem quality in study area was generally poor. The areas with poor grades were mainly distributed in the northwestern, northeastern and southeastern parts of the study area. The ecological environment quality of most parts of the study area was of ordinary grade, and the moderate-level land was mainly distributed in the central and southwestern parts of the study area, while the area with good evaluation grade accounted for the smallest proportion of the total area of the study area and was scattered throughout the study area. In 2008, the ecological environment quality evaluation result of the study area was significantly improved as compared with that of 1998. The poorly graded area was distributed in the northwestern part of the study area, and the area was significantly reduced as compared with that in 1998. The ordinary grade area did not change as compared with that in 1998. The area of the moderate and excellent area was slightly higher than that of 1998, while the area with excellent grades was almost unchanged. In 2017, the ecological environment quality of the study area was changed most obviously. The area with poor ecological environment quality almost disappeared. The ordinary grade area was significantly
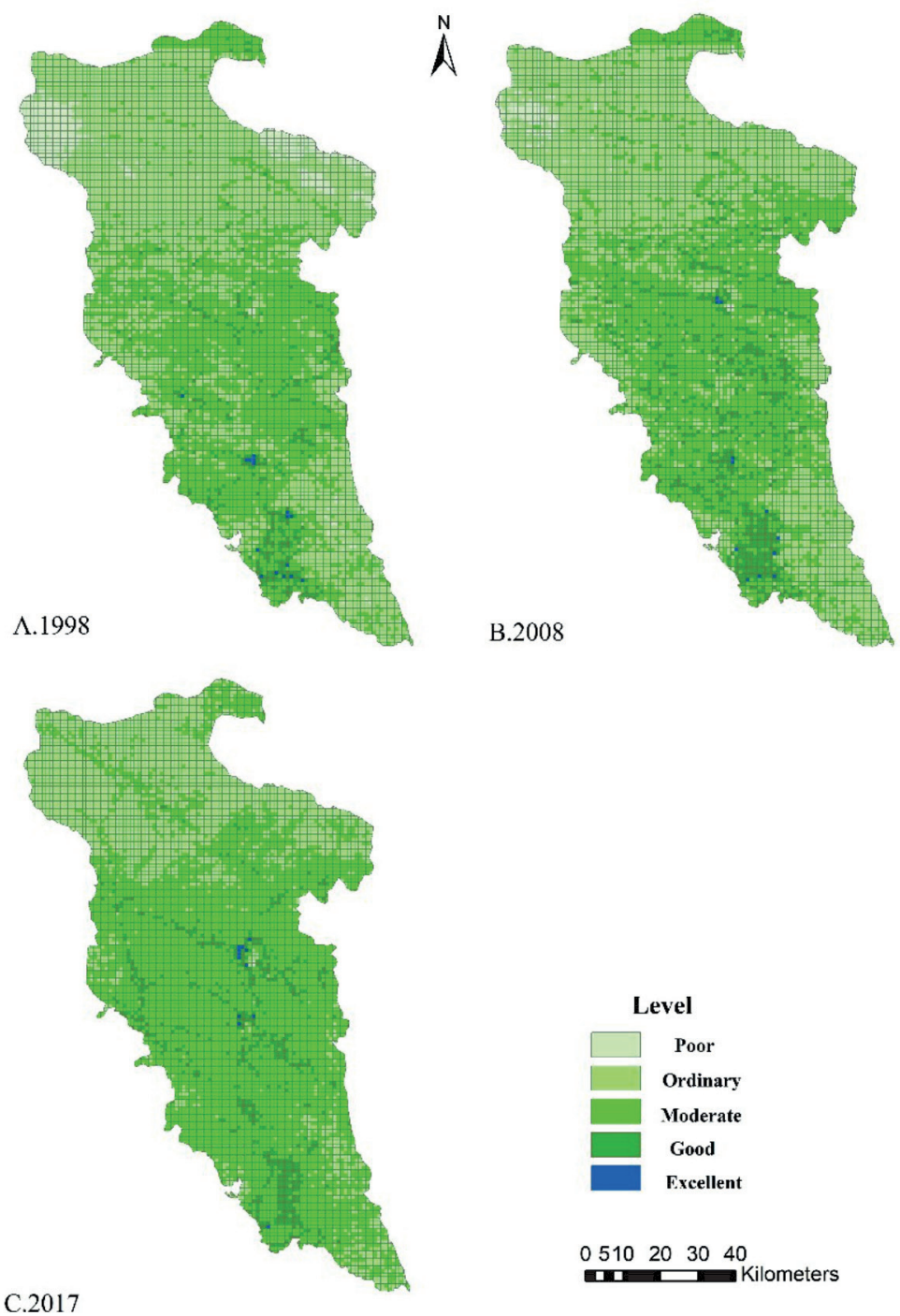

$0510 \quad 20 \quad 30 \quad 40$

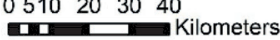

Fig. 4. Ecological environment quality evaluation results in the study area. 
Table 2. Ecological environment quality grade area and proportion in the study area.

\begin{tabular}{|c|c|c|c|c|c|c|}
\hline & \multicolumn{2}{|c|}{1998} & \multicolumn{2}{|c|}{2008} & \multicolumn{2}{c|}{2017} \\
\hline $\begin{array}{c}\text { Ecological environment } \\
\text { quality level }\end{array}$ & Area/km² & Proportion (\%) & Area/km² & Proportion (\%) & Area//km ${ }^{2}$ & Proportion (\%) \\
\hline Poor & 441.22 & 5.23 & 122.14 & 1.45 & 3.93 & 0.05 \\
\hline Ordinary & 4528.79 & 53.67 & 4139.65 & 49.05 & 2636.47 & 31.24 \\
\hline Moderate & 3132.7 & 37.12 & 3644.09 & 43.19 & 5206.88 & 61.71 \\
\hline Good & 319.58 & 3.79 & 520.41 & 6.17 & 579.01 & 6.86 \\
\hline Excellent & 16 & 0.19 & 12 & 0.14 & 12 & 0.14 \\
\hline
\end{tabular}

reduced and mainly distributed in the northern part of the study area. The area with moderate grade accounted for the largest proportion of the area of the study area. Compared with that in 2008, it was increased significantly, while the areas with good and excellent grades were slightly increased as compared with that in 2008.

It can be seen from Table 2 that in the past 20 years, the ecological environment quality of the study area was significantly lower than that of the general grade. The area with moderate grade was increased in a large area, and the change in area with the good and excellent grade was smaller. The area with poor grade was dropped from $441.22 \mathrm{~km}^{2}$ in 1998 to $122.14 \mathrm{~km}^{2}$ in 2008 and has dropped to $3.93 \mathrm{~km}^{2}$ in 2017; The area with ordinary grade was decreased from $4,528.79 \mathrm{~km}^{2}$ in 1998 to $4,139.65 \mathrm{~km}^{2}$ in 2008 , and its area was $2,364.47 \mathrm{~km}^{2}$ in 2017 , and its proportion was decreased to $22.43 \%$; the area with moderate grade changed significantly, and the area in 1998, it was only $3132.7 \mathrm{~km}^{2}$, rising to $3644.09 \mathrm{~km}^{2}$ in 2008 , and has risen to $5206.88 \mathrm{~km}^{2}$ in 2017 , with a rising proportion being $24.59 \%$; the area with good ecological environment quality was increased from $319.58 \mathrm{~km}^{2}$ in 1998 to $579.01 \mathrm{~km}^{2}$ in 2017 while the quality of ecological environment of the study area was almost unchanged.
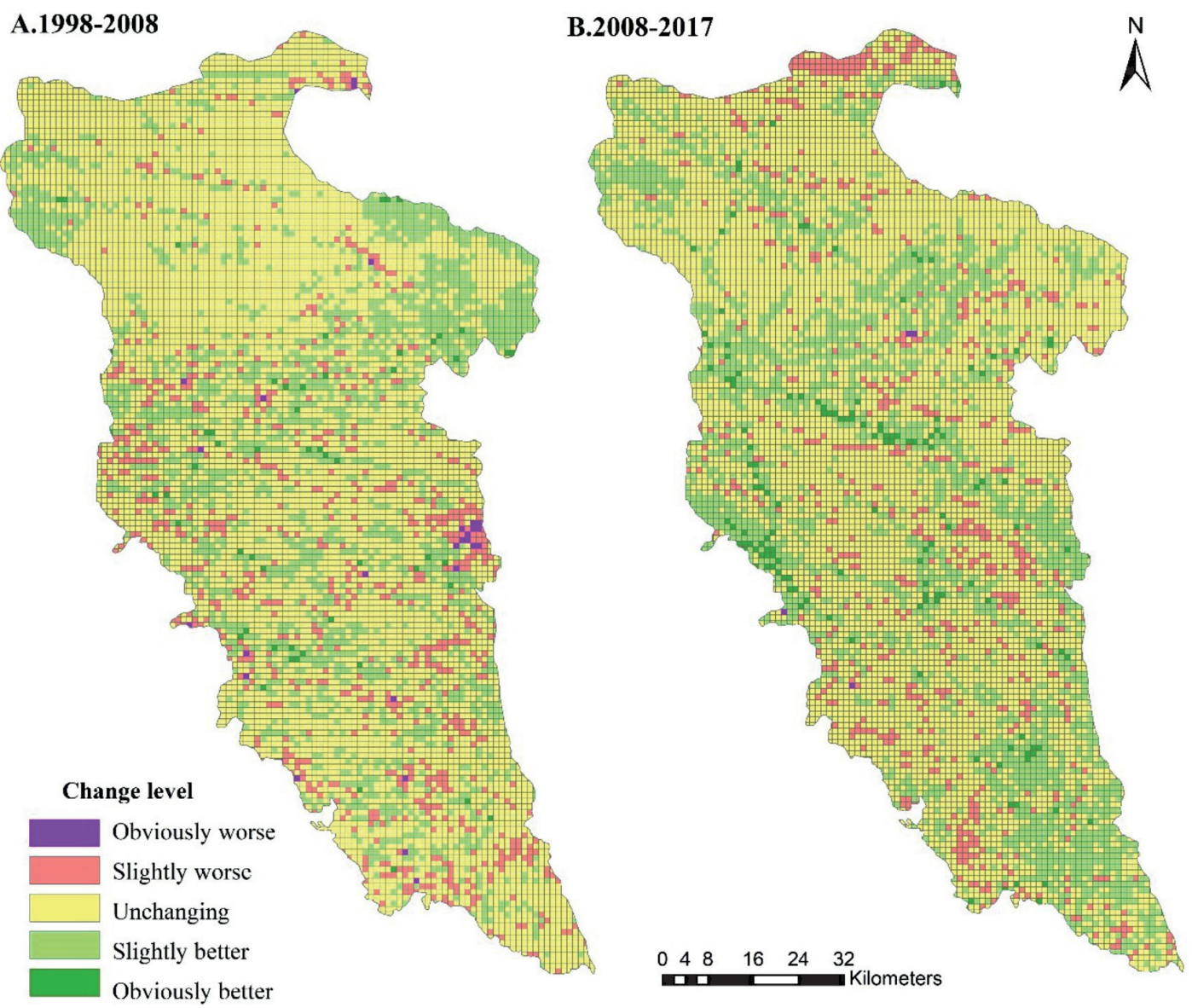

Fig. 5. Ecological environment quality change map in the study area. 


\section{Analysis of Change in Ecological Environment Quality and Spatial Correlation}

\section{Analysis of the Changes in Ecological Environment Quality}

Based on the results of ecological environment quality evaluation in the study area for a period of nearly 20 years, change map in the ecological environment quality of the study area from 1998 to 2017 was drawn (Fig. 5), and the change types were divided into five grades: significant deterioration $(-0.4,-0.2)$; slightly worse $(-0.2,-0.05)$, unchanged $(-0.05,0.05)$, slightly better $(0.05,0.2)$, and significantly better $[0.2,0.4)$, and statistical changes in various areas (Table 3). The land use change condition and other basic data in the study area were used to analyze the causes for the changes in ecological environment quality in the study area within the past 20 years.

It can be seen from Table 3 that the area of the Danjiang River Basin (Henan Section) with significantly worsened ecological environment quality between 1998 and 2008 reached $27.57 \mathrm{~km}^{2}$, and the area with significant deterioration from 2008 to 2017 was $4 \mathrm{~km}^{2}$. Compared with that in the past 20 years, the study area of the ecological environment with significantly degraded ecological environment quality was only $2.77 \mathrm{~km}^{2}$. The area with slightly worsened ecological environment quality ranged from $748.90 \mathrm{~km}^{2}$ between 1998 and 2008. The area was decreased slightly to only $705.61 \mathrm{~km}^{2}$ between 2008 and 2017, while the slightly degraded area in the past 20 years was only $425.63 \mathrm{~km}^{2}$. The area with slightly better ecological environment quality was $1915.36 \mathrm{~km}^{2}$ in the first 10 years and was increased to $2231.76 \mathrm{~km}^{2}$ in the last 10 years, and slightly improved in the last 20 years to $3121.12 \mathrm{~km}^{2}$. The area that was obviously better was also increased. From $54.41 \mathrm{~km}^{2}$ in the previous 10 years to $140.03 \mathrm{~km}^{2}$ in the last 10 years, the area with a significantly better ecological environment quality in the past 20 years had reached $164.19 \mathrm{~km}^{2}$. In summary, over the last two decades, the ecological environment quality of a larger proportion of the changed area in the Danjiang River Basin (Henan section) has been slightly improved. This change indicates that the habitat quality in the study area has been continuously improved.

\section{Spatial Correlation Analysis}

Spatial statistical analysis mainly used statistical methods to classify and comprehensively evaluate spatial data, which core is to analyze spatial positional relationships through spatial data [41]. In this study, the changes of ecological environment quality in the study area in the past 20 years were taken as spatial variables, and the spatial distribution characteristics were studied, which is helpful to analyze the change trend and evolution mechanism of ecological environment quality. Spatial autocorrelation analysis measured the autocorrelation and correlation of a variable in spatial distribution and was usually calculated using the Moran's I index. To further reveal the local spatial heterogeneity of the variables, the spatial heterogeneity distribution was represented by the Local Spatial Correlation ${ }^{\mathrm{i}}$ ndex (LISA).

GeoDa software was used to perform a spatial autocorrelation analysis of changes in the quality of the ecological environment in the study area over the past 20 years. The results were plotted as Moran scatter plot and LISA index spatial aggregation map, and combined with the land use transfer matrix of the research area for nearly 20 years. The causes for the changes in ecological environment quality in the area were analyzed.

The spatial autocorrelation calculation of the change in ecological environment quality showed that the global Moran's I index was 0.5122 and the Z-score was 7.4368 , indicating that the ecological environment quality variation distribution in the study area showed a significant and spatially positive correlation, and there was an obvious spatial aggregation distribution phenomenon, that is, the area where the ecological environment quality was better, the ecological environment quality around it is also getting better, and vice versa. It can be seen from Moran's scatter plot that the $\mathrm{H}-\mathrm{H}$ quadrant represents an increase in ecological environment quality while the L-L quadrant represents a decline in ecological environment quality. The L-H quadrant represents showed that a portion of the ecological environment quality was reduced with elevated ecological environment quality, and the H-L quadrant represents a portion of the ecological environment quality. The areas with high ecological environment quality were surrounded by areas of reduced ecological environment quality.

Table 3. Area of ecological environment quality change in the study area (unit: $\mathrm{km}^{2}$ ).

\begin{tabular}{|c|c|c|c|}
\hline Change level & $1998-2008$ & $2008-2017$ & $1998-2017$ \\
\hline Obviously worse & 27.57 & 4.00 & 425.63 \\
\hline Slightly worse & 748.90 & 705.61 & 4724.58 \\
\hline Unchanging & 5692.05 & 5356.90 & 3121.12 \\
\hline Slightly better & 1915.36 & 2231.76 & 164.19 \\
\hline Obviously better & 54.41 & 140.03 & \\
\hline
\end{tabular}




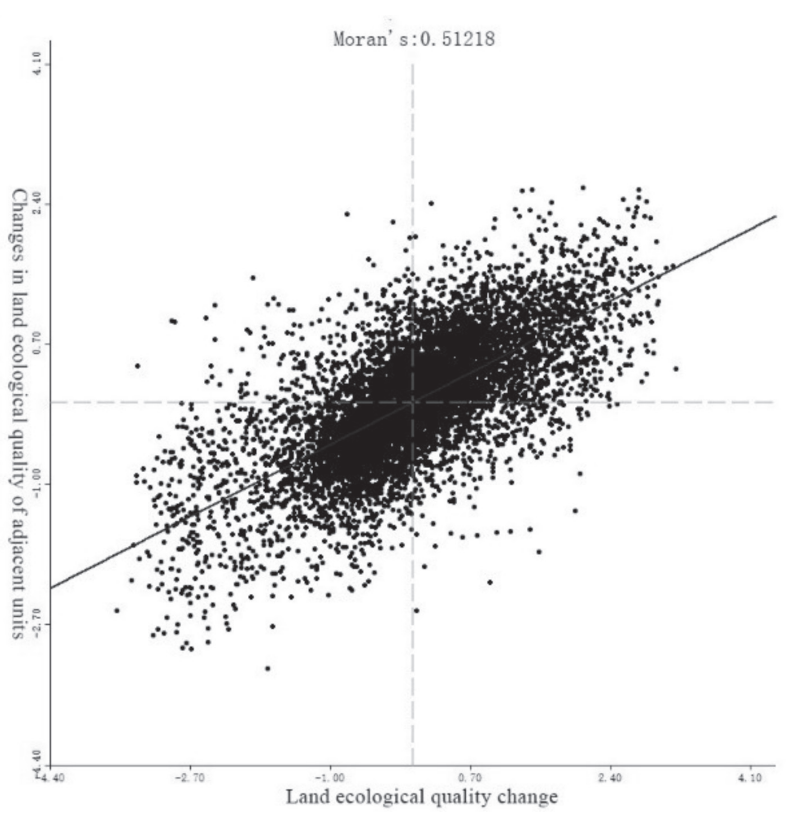

Fig. 6. Moran scatter plot of ecological environment quality change in the study area.

Through the analysis of the spatial aggregation characteristics of the LISA index of ecological environment quality change in the study area in the past 20 years, there were 998 high-high clusters, accounting for $11.21 \%$ of the total area of the study area. It can be saw from the figure that the areas with better ecological environment quality in the study area are mainly concentrated in the northeast, west and southeast parts of the study area. Combined with the land use change map (Fig. 1) and the land use type transfer matrix (Table 4) in the study area, we found that the main land use types in the northeast and west were forest land, and the implementation of the policy of returning farmland to forests was the cause for the improvement of ecological environment quality. From the land use transfer matrix of the study area, it can be found that the net conversion area of cultivated land to forest land in the past 20 years was $392.55 \mathrm{~km}^{2}$, and the increase of vegetation coverage in the lower slope area led to the

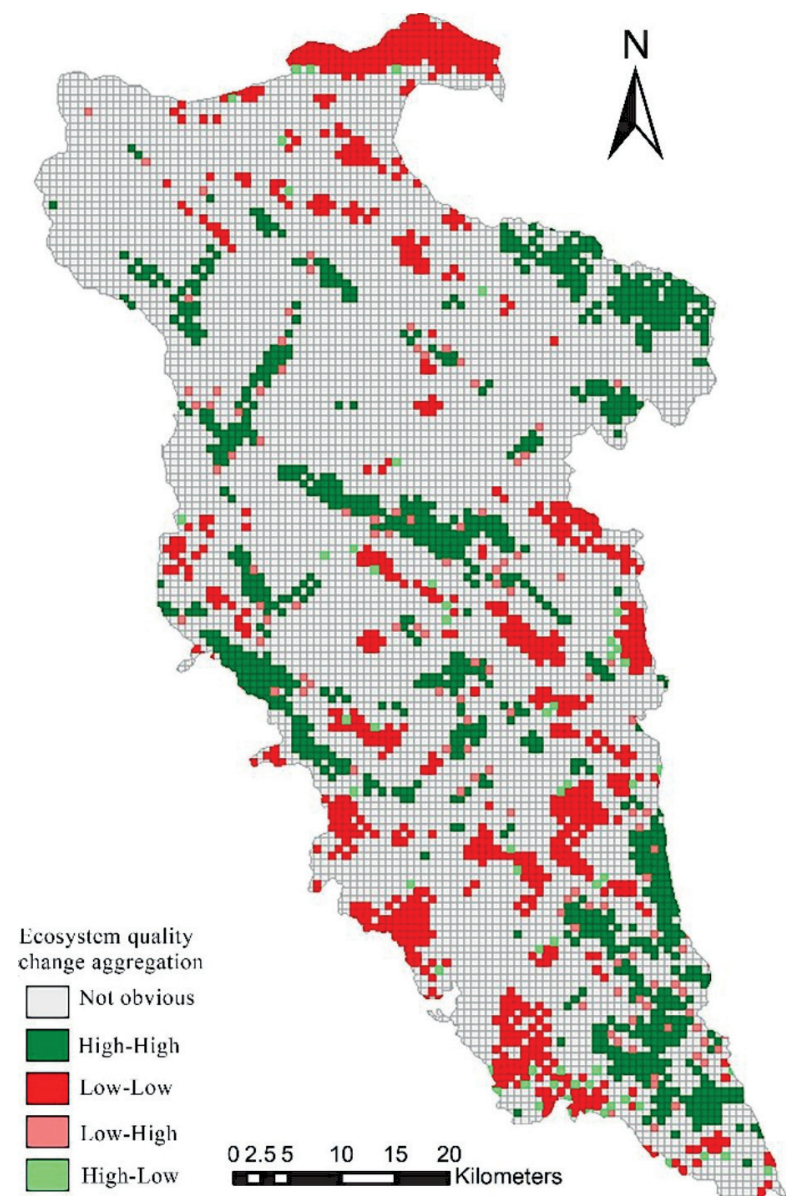

Fig. 7. LISA aggregation map of ecological environment quality change in study area.

improvement of the ecological environment quality of the area; The land use types in the southeastern part were mainly the cultivated land and grassland, and they are located in the main canal area of the South-to-North Water Transfer Project. The cause for the improvement of ecological environment quality may be related to the overall ecological planning of the region. There were 909 low-low accumulation areas, accounting for $10.31 \%$ of the total area, which was mainly concentrated in the northern, western and southeastern parts of

Table 4. Land use type transfer matrix of study area in 1998-2017(unit: $\mathrm{km}^{2}$ ).

\begin{tabular}{|c|c|c|c|c|c|c|c|}
\hline \multirow{3}{*}{ Years } & \multicolumn{7}{|c|}{$1998-2017$} \\
\cline { 2 - 9 } & Types & Woodland & Grassland & Arable land & Construction land & Waters & Bare land \\
\hline \multirow{7}{*}{1998} & Woodland & 3814.74 & 206.49 & 61.64 & 12.89 & 14.07 & 5.67 \\
\cline { 2 - 9 } & Grassland & 419.87 & 1028.85 & 400.15 & 69.20 & 14.39 & 98.92 \\
\cline { 2 - 9 } & Arable land & 454.19 & 43.59 & 943.90 & 122.15 & 37.31 & 136.39 \\
\cline { 2 - 9 } & $\begin{array}{c}\text { Construction } \\
\text { land }\end{array}$ & 0.64 & 11.95 & 28.10 & 43.82 & 23.83 & 9.55 \\
\cline { 2 - 9 } & Waters & 0.69 & 1.81 & 9.69 & 3.66 & 320.23 & 1.03 \\
\cline { 2 - 9 } & Bare land & 0.53 & 24.76 & 27.27 & 14.89 & 10.37 & 21.06 \\
\hline
\end{tabular}


the study area. At the same time, there are also some areas where the changes in the surrounding ecological environment quality were abnormal, that is, low-high type and high-low type areas, which were scattered in the study area. Among them, the low-high anomaly area represents the area where ecological environment quality declines was surrounded by the area where the ecological environment quality was increased. This change indicates that the ecological environment quality of this area is abnormally decreased. On the other hand, the high-low anomaly area represents the area whose ecological environment quality increases was surrounded by the area where the ecological environment quality was declined. This change indicates the ecological environment quality of the area is abnormally increased.

\section{Conclusions}

Based on the data for land use type, natural conditions and socio-economic development of Danjiang River Basin (Henan Section) in this study, we selected the ecological environment quality evaluation index of the study area based on the ecological basis, ecological structure, ecological benefit and ecological stress. The evaluation unit of the study area adopted the improved variable fuzzy set model, and used ArcGIS software to quantitatively evaluate the ecological environment quality and the level and area of the ecological environment quality in the study area. The results show that the ecological environment quality of the study area has shown a good trend in recent years. Among them, the area changes in the ecological environment quality in the central area from 3132.7 $\mathrm{km}^{2}$ in 1998 to $3644.09 \mathrm{~km}^{2}$ in 2008 , and has risen to $5206.88 \mathrm{~km}^{2}$ in 2017 was the most significant one. The area with ordinary grade was dropped from 4,528.79 $\mathrm{km}^{2}$ in 1998 to $4,139.65 \mathrm{~km}^{2}$ in 2008 , and to $2,364.47$ $\mathrm{km}^{2}$ in 2017 , a decrease of $22.43 \%$. Furthermore, the autocorrelation analysis of ecological environment quality changes in the study area showed that the global Moran's I index was 0.5122, indicating that the distribution of ecological environment quality changes shows significant spatial autocorrelation. It can be seen from the spatial aggregation feature map of LISA index that the change in ecological environment quality in the study area is closely related to human activities. The expansion of construction land and the increasing population are the main factors causing the decrease of ecological environment quality in the study area while the area with improved ecological environment quality was closely related to the increase of vegetation coverage in mountainous areas and the protection of cultivated land.

As the water source of the Middle Route of the South-to-North Water Transfer Project, the ecological environment quality of Danjiang River Basin (Henan Section) in the past 20 years has been gradually improved, indicating that the ecological status of the study area has been gradually improved. However, its ecological environment quality in some other areas mainly with the expansion of construction land was declined. The declined ecological environment quality is related to disturbance of human activities. Therefore, in the process of urbanization development, it is necessary to pay particular attention to the coordinated development of the economy and the ecological environment, further promoting the coordination of human-land relations, and continuously improving the ecological environment quality of the research area and achieving sustainable development.

\section{Acknowledgments}

This research was supported by National Natural Science Foundation of China (No. 41801318), Henan Province Key projects of science and technology research (192102310038,192102310270), Fundamental Scientific Research Funds for Colleges and Universities in Henan Province (NSFRF1630), Innovative research team fund of Henan Polytechnic University (T2017-4) and Henan Province University Science and Technology Innovation Team Support Program (18IRTSTHN008). We also want to express our respect and thanks to the anonymous reviewers and the editors for their helpful comments in improving the quality of this paper.

\section{Conflict of Interest}

The authors declare no conflict of interest.

\section{References}

1. FLESKENS L., DUARTE F., EICHER I. A conceptual framework for the assessment of multiple functions of agro-ecosystems: A case study of Trás-os-Montes olive groves. Journal of Rural Studies, 25(1), 141, 2009.

2. YUAN F. Land-cover change and environmental impact analysis in the Greater Mankato area of Minnesota using remote sensing and GIS modelling[J]. International Journal of Remote Sensing, 29 (4),1169, 2008.

3. HUANG S.L., WANG S.H., BUDD W.W. Sprawl in Taipei's peri-urban zone: Responses to spatial planning and implications for adapting global environmental change. Landscape \& Urban Planning, 90 (1-2), 20, 2009.

4. PAN Y., CUI L.L., LIU C.M., CHEN L., ZHANG L.F. Spatiotemporal distribution of urban heat island effect based on MODIS data in Chongqing, China. Chinese Journal of Ecology, 37 (12), 3736, 2018.

5. YANG B., FANG H.Y., XU L.L., ZHONG Q.P., LI S.S. Characteristics and driving factors of spatio-temporal changes of water pollution in Qinzhou Bay. Marine Environmental Science, 36 (6), 877, 2017.

6. ZHAO G.S., LIU J.Y., KUANG W. H., OUYANG Z .Y., XIE Z.L. Disturbance impacts of land use change on biodiversity conservation priority areas across China: 
1990-2010. Journal of Geographical Sciences, 25 (5), 515, 2015.

7. LIU C.Y., ZHU K.W., LIU J.P. Evolution and prediction of land cover and biodiversity function in Chongqing section of Three Gorges Reservoir Area. Transactions of the Chinese Society of Agricultural Engineering, 33 (19), 258, 2017.

8. XIAO M. The Application of GIS in Watershed Ecological Quality Evaluation - A case study in ChangHuaJiang Downstream. Hainan University, 2011.

9. WU J.S., CAO Q.W., SHI S.Q., HUANG X.L., LU Z.Q. Spatio-temporal variability of habitat quality in BeijingTianjin-Hebei Area based on land use change. Chinese Journal of Applied Ecology, 26 (11), 3457, 2015.

10. XIA J. Regional Water Environment and Ecological Environment Quality Assessment: Theory and Application of Multi-Level Association Assessment. Publisher: Wuhan, China, 24, 1999.

11. ZHANG H.F., HU H., SU L.N., CHE L.F., FENG T., LIU Y., LI D.F., WU X.M. Habitat Suitability Assessment of Musk Deer (Moschus sifanicus) in Sanjiangyuan Nature Reserve, Qinghai Province. Acta Agriculture Borealioccidentalis Sinica, 26 (8), 1141, 2017.

12. YAN R., FAN J.T., XU S.N., XU Y.W., SUN M.S. Distribution characteristics of jack mackerel (Trichuris japonicus) habitat in the offshore waters of northern South China Sea. Chinese Journal of Ecology, 37 (8), 2430, 2018.

13. SHERROUSE B.C., SEMMENS D.J., CLEMENT J.M. An application of Social Values for Ecosystem Services (SolVES) to three national forests in Colorado and Wyoming. Ecological Indicators, 36, 68, 2014.

14. LI X., LI Y., FANG Y.M. Prediction of Potential Suitable Distribution Areas of Quercus fabri in China Based on an Optimized Maxent model. Scientia Silvae Sinicae, 54 (08), 156, 2018.

15. LI M.L., CHEN Q.Q., WANG M.Y., YANG W.K. Assessment of habitat suitability of Ovis ammon polii based on MaxEnt modeling in Taxkorgan Wildlife Nature Reserve. Chinese Journal of Ecology, 38 (2), 594, 2019.

16. LEH M.D.K., MATLOCK M.D., CUMMINGS E.C., NALLEY L.L. Quantifying and mapping multiple ecosystem services change in West Africa. Agriculture, Ecosystems \& Environment, 165, 6, 2013.

17. LIU Z.F., TANG L.N., QIU Q.Y., XIAO S., XU T., YANG L. Study on the Spatial and Temporal Changes of Habitat Quality in Fujian Province Based on Land Use Change. Acta Ecologica Sinica, 37 (13), 4538, 2017.

18. REDHEAD J.W., MAY L., OLIVER T.H., HAMEL P., SHARP R., BULLOCK J.M. National scale evaluation of the InVEST nutrient retention model in the United Kingdom. Science of the Total Environment, 610, 666, 2018.

19. MOREIRA M., FONSECA C., VERGÍLIO M., CALADO H., GIL A. Spatial assessment of habitat conservation status in a Macaronesian island based on the InVEST model: a case study of Pico Island (Azores, Portugal). Land Use Policy, 78, 637, 2018.

20. SUN D.Q., ZHANG J.X., ZHU C.G., HUY., ZHOU L. An Assessment of China's Ecological Environment Quality Change and Its Spatial Variation. Acta Geographica Sinica, 67 (12), 1599, 2012.

21. LIU H., CAI Y., YU M.Q., GONG L.T., AN S.Q. Assessment of river habitat quality in Yixing district of Taihu Lake basin. Chinese Journal of Ecology, 31 (5), 1288, 2012
22. YANG J.Q., ZHU Y.G., SONG W.P., ZHANG J., ZHANG L.J., LUO X.X. Ecological Environment Quality Evaluation of Laizhou Bay Based on Habitat Quality and Ecological Response. Acta Ecologica Sinica, 34 (1), 105, 2014.

23. CHEN M., SU X.L., HUANG H.M., GAO T., DANG C.Q., DONG R., ZENG B., TAO J.P. Assessment of river habitat quality in the Three Gorges Reservoir Region. Acta Ecologica Sinica, 39 (1), 192, 2019.

24. XU H.Q. A remote sensing urban ecological index and its application. Acta Ecologica Sinica, 33(24), 7853, 2013.

25. XU H.Q. A remote sensing index for assessment of regional ecological changes. China Environmental Science, 33 (5), 889, 2013.

26. GOWARD S.N., XUE Y., CZAJKOWSKI K.P. Evaluating land surface moisture conditions from the remotely sensed temperature/vegetation index measurements: An exploration with the simplified simple biosphere model. Remote Sensing of Environment, 79 (2-3), 225, 2002.

27. BAIG M. H.A., ZHANG L.F., TONG S. Derivation of a tasselled cap transformation based on Landsat 8 at-satellite reflectance. Remote Sensing Letters, 5 (5), 423, 2014.

28. YU H., ZENG H., JIANG Z.Y. Study on Distribution Characteristics of Landscape Elements along the Terrain Gradient. Scientia Geographica Sinica, 21 (1), 64, 2001.

29. XIAO Y., ZHU F.W., ZHOU S.L., SHEN C.Z., WANG J. Key Landscape Pattern Factors Affecting Land Ecological Quality in Developed Areas: A Case Study of Kunshan City in Jiangsu Province. Journal of Natural Resources, 32 (10), 1731, 2017.

30. WANG S.D., SHEN L., WANG X.C. Evaluation of ecological land based on RS and GIS: A case study of Dawa County, Liaoning Province. Chinese Journal of EcoAgriculture, 21 (5), 628, 2013.

31. COSTANZA R., D'ARGE R., GROOT R. The value of the world's ecosystem services and natural capital. Nature, 387 (15), 253, 1997.

32. XIE G.D., LU C.X., LENG Y.F., ZHENG D., LI C.S. Ecological assets valuation of the Tibetan Plateau. Journal of Natural Resources, 18 (2), 189, 2003.

33. VEISI H., LIAGHATI H., ALIPOUR A. Developing an ethics-based approach to indicators of sustainable agriculture using analytic hierarchy process (AHP). Ecological Indicators, 60, 644, 2016.

34. XU S.B., XU D.S., LIU L.L. Construction of regional informatization ecological environment based on the entropy weight modified AHP hierarchy model. Sustainable Computing: Informatics and Systems, 22, 36, 2019.

35. CHEN S.Y. Theory and model of engineering variable fuzzy set - Mathematical basis for fuzzy hydrology and water resources. Journal of Dalian University of Technology, 4(2), 308, 2005.

36. CHEN S.Y. Philosophical foundation of variable fuzzy sets theory. Journal of Dalian University of Technology (Social Science), 26 (1), 53, 2005.

37. CHEN S.Y., CHAI C.L., SU Y.N. Variable fuzzy sets methods and application on land suitability evaluation. Transactions of the Chinese Society of Agricultural Engineering, 23 (3), 95, 2007.

38. CHEN S.Y. Theory of variable fuzzy sets and variable model sets. Mathematics in Practice and Theory, 38 (18), 146, 2008. 
39. LIU S.F., XIE N.M. New grey evaluation method based on reformative triangular whitenization weight function. Journal of Systems Engineering, 26 (2), 244, 2011.

40. PAVLAČKA O. On various approaches to normalization of interval and fuzzy weights. Fuzzy Sets \& Systems, 243, 110, 2014.
41. ZHANG F., YUSHANJIANG A., JING Y.Q. Assessing and predicting changes of the ecosystem service values based on land use/cover change in Ebinur Lake Wetland National Nature Reserve, Xinjiang, China. Science of The Total Environment, 656, 1133, 2019. 